committee will choose, in the next session of Congress, to resolve this situation. It is unlikely that the US Army and the AEC will willingly abandon the work they have been doing. No doubt much weight will be given to the recommendation of the Committee on Radiation Preservation of Food of the National Academy of Sciences which said in a report on July 25,
1968 , that the evidence against irradiated ham is not conclusive, that irradiation may still become an important method of food preservation and that the best course now would be a study by an independent group under the aegis of the National Academy of Sciences with the first objective of establishing criteria of wholesomeness.

\title{
Double Vision in Fine Optics
}

People in Jena will not have been surprised by the news that the United States District Court in New York has ruled in favour of the West German version of the Carl Zeiss Foundation. The legal battle between Carl Zeiss of Oberkochen in West Germany and Carl Zeiss of Jena in the German Democratic Republic has become something of a saga. So far, judiciaries in various parts of the world have tended to rule along political lines; in the eastern bloc, for instance, every court decision has been in favour of Jena, while in the west-most recently in France, Ttaly and EgyptOberkochen has had the better of it.

The argument arose after the war, when Jena fell into the Russian zone. As the American forces left, they took with them a group of Zeiss scientists and engineers from Jena, where the optical firm of Carl Zeiss had long been established. The emigrés went to Oberkochen in Baden-Württemberg, where they set up a new firm, making identical products and bearing the Carl Zeiss name. Those that had remained in Jena rebuilt the firm there and met with increasing success, as did the West Germans. The growing sales of both organizations was bound in the end to provoke an outright clash, which came in 1954, when legal proceedings began. They are still in progress in many parts of the world, including Britain.
Judge Walter R. Mansfield, delivering the District Court verdict, declared that the East German version of Zeiss was a "pseudo-type organization, deliberately established in East Germany as a sham or façade for litigation purposes", a judgment with which few who have visited Jena would concur. He said that Carl Zeiss of West Germany is the exclusive owner in the United States of the trade name Carl Zeiss, and that Zeiss Ikon AG of Stuttgart was the exclusive owner of the Zeiss Ikon name. Subject to the resolution of certain issues which remain to be tried, West German Zeiss will be able to prevent the East German company from using the trademark.

This is likely to produce a difficult situation for Jena. Barring appeals, the most likely course for the Jena concern to take would be to sell in the US under another name-perhaps the "Aus Jena" name which they have already used in West Germany. Whatever the legal intricacies, scientists are inclined to say that both versions of Carl Zeiss produce good products, and are likely to go on buying from both. In Britain, there seems to be no immediate prospect that the legal battle can be settled. The most recent decision, involving a technicality about the position of the West German solicitors, went in favour of Oberkochen.

\section{Claim for Sustained Boom in Mathematics}

A commitree of the National Academy of Sciences in Washington has now come out with a powerful argument for sustained support of research and education in mathematics (The Mathematical Sciences-A Report, National Academy of Sciences publication 1681). The report is one of a series commissioned by the Committec on Science and Public Policy, and has been prepared by a committee of mathematicians with Professor Lipman Bers of Columbia as chairman. The committee says in its report that the community of mathematicians "has no obligations more important than those concerned with education", which is why the committee is planning to publish separately a volume dealing with undergradutae education.

Even where the report will be regarded as a piece of special pleading by the mathematicians, its demonstration of the importance of mathematics in the modern world will be exceedingly hard to counter. The flat statement that there are already more computer programmers than high school teachers of mathematics in the United States shows which way the wind is blowing. In making its claim for further support for mathematics, however, the committee does not belittle what it calls the "stupendous" effect of government support for mathematics in the past twenty years, which has turned the United States from a consumer of mathematical talent clsewhere into a "leading producer". By way of illustration, the committee points out that a third of the invited speakers at the past four international congresses have been from the United States, that there has been a steady increase in the number of references to the American mathematical literature in journals published outside the United. States, and that there has also been a steady increase in the number of forcign mathematicians visiting the United States.

On the level of federal support for research in mathematics, the committee acknowledges the quite rapid increases of recent years. Between them, Federal agencies seem to have spent $\$ 23.6$ million on mathematical research of all kinds in 1960, and just under $\$ 125$ million-or more than five times as much-in 1966. Of the Federal agencies, the US Air Force is the most generous supporter (with $\$ 33$ million in 1966.) Roughly $\$ 35$ million of the US Government's expenditure on mathematics scems to find its way directly to 